\title{
The Teaching Mode Study of Mechanical Design Courses Oriented to Engineering Education
}

\author{
Zeguang Han* \\ College of Mechanical Engineering \\ Shenyang Jianzhu University \\ Shenyang, China
}

\author{
Ruiqin Hao \\ College of Mechanical Engineering \\ Shenyang Jianzhu University \\ Shenyang, China
}

\begin{abstract}
Engineering education should always be oriented towards engineering practice. In the context of engineering education reform and engineering certification in the new era, this paper draws on CDIO and other advanced educational concepts at home and abroad, and puts forward SPCGR teaching mode suitable for China's national conditions and school conditions, expounds the connotation of SPCGR and the relationship between SPCGR and engineering certification, SPCGR and CDIO, and introduces the application advantages of SPCGR teaching mode in single course and course group. The above measures lay a solid foundation for the realization of the curriculum reform driven by software and projects, and the organic integration of project training, software use, theoretical teaching and experimental teaching and other teaching links. After five years of attempts in a few courses, good teaching results have been achieved, indicating that SPCGR teaching is effective for engineering education and is an effective means to train students to solve complex engineering problems.
\end{abstract}

Keywords-engineering education; SPCGR; CDIO; engineering certification

\section{INTRODUCTION}

The goal of engineering education is to provide students with all the nutrients they need to become a qualified engineer, that is, expertise, social awareness and a spirit of innovation $[1,2]$. In order to achieve this goal, the higher education workers need to continuously improve the quality of undergraduate education and the connotation. Therefore, in the teaching process, in addition to the course teaching of traditional knowledge, teamwork project, knowledge expansion method, series of between course knowledge and the experience of the new technology to solve the problem should be an important part of the complete engineering education class.

In the past 30 years, educational institutions around the world have set off a trend of engineering education reform, put forward and tried a variety of educational teaching mode, obtained some results, accumulated valuable experience. The successful educational modes seem to be the CDIO mode, an OBE engineering education mode, a problem or project-based learning-PBL educational mode proposed by Aalborg University, Denmark, or an experience-based manner, organized by Imperial College, United Kingdom.
The reform of engineering education is an important foundation for improving the ability of cultivating innovative talents in universities and realizing the goal of building an innovative society. Compared with engineering education methods in European and American universities, engineering education in Chinese universities mostly continues the examoriented education method, and students generally learn in a passive way, which leads to an obvious lack of innovation ability and enthusiasm. At the same time, educators generally realize that any advanced teaching concept and talent training mode reform must be adapted to their own national conditions and school conditions, and any copying mode is difficult to receive satisfactory expected results. Therefore, it is imperative to explore suitable reform methods of engineering education. At present, a few domestic universities with sufficient teaching funds and abundant teaching resources have adopted the smallclass teaching mode of recruiting innovation classes. During the teaching process, they have tried CDIO and other new teaching modes, and achieved success in training innovative talents with a small audience. However, facing the situation of large number of students, relatively lack of teachers and teaching resources, it is more constructive for most colleges and universities to explore an effective engineering education model and continuously improve and implement it for a long time to ensure that it can reach a wide audience. The College of Mechanical Engineering of Shenyang Jianzhu University has been trying the teaching mode of SPCGR in the mechanical design courses for five years in combination with the characteristics of our school, and has received good teaching results.

This paper will expound the connotation of SPCGR, the relationship between SPCGR and engineering certification, and the relationship between SPCGR and CDIO, and finally verify the effectiveness of SPCGR teaching mode on engineering education through examples. SPCGR teaching mode has a broad application prospect because of its good expansibility in the course group.

\section{THE CONNOTATION OF SPCGR}

SPCGR is an acronym for Software, Project, Class, Group, and Reformation. SPCGR teaching mode means to form groups among courses and complete the teaching activity organization process of the group under the cooperation of software tools and projects, so as to realize the goals of linkage 
reform, dynamic decomposition of content and extension and application of knowledge. In the course learning process, SPCGR teaching is properly implemented, which can combine knowledge with practice and apply knowledge to practice. SPCGR is applicable to both single course and course group. For example, Mechanical design is a basic course of mechanical engineering. It is also the connection bridge of mechanical drawing, engineering mechanics, mechanical principle, manufacture technology, computer application software tools and subsequent professional backbone courses. If these courses around the mechanical design of class group, parallel reform within the group, content of organic decomposition and extended application in accordance with the process of curriculum, the students' ability application knowledge to solve practical engineering problems will be fully exercised.

The reform of a single course has been carried out for many years, and the achievements in the teaching process are beyond doubt. However, the concurrent reform of the composition of several closely related main courses has not been widely used in the teaching of engineering courses in Chinese universities. As is known to all, nowadays computer application technology has entered a period of rapid development, whether scientific research or product development is increasingly inseparable from the support of computer software tools. Virtual design and simulation in software environment has become an indispensable link in the whole product cycle. Learning and mastering various related virtual design and simulation software has become a necessary ability for practitioners in the field of engineering. College students have a natural advantage in accepting new technologies, and they have a strong interest in the application of new technologies. Using new technologies to connect and extend knowledge in class groups can stimulate students' learning enthusiasm. We were pleasantly surprised to find that almost every mechanical design course could be supported by professional software (see Table I). If the application of software is integrated into the course knowledge teaching, it will get twice the result with half the effort for students to master the knowledge and get good results.

TABLE I. SOFTwARE TOOLS FOR MECHANICAL DESIGN COURSES

\begin{tabular}{|c|c|}
\hline Course name & Software tools \\
\hline mechanical drawing & AutoCAD, SolidWorks, ProE \\
\hline engineering mechanics & MATLAB \\
\hline mechanical principle & MATLAB, ADAMS \\
\hline mechanical design & AutoCAD, MATLAB, ANSYS \\
\hline manufacture technology & MasterCam \\
\hline hydraulic transmission & Simulink \\
\hline
\end{tabular}

In the implementation of SPCGR teaching, project setting is the core, and it is also the key for students to gain knowledge understanding, application and even innovation in the course learning. The specific requirements of the project setting are: (1) the project has integrity. (2)The project is real. (3) Projects are closely related to theoretical knowledge.
SPCGR teaching can be seen to some extent as a rehearsal for a design activity. Through reasonable decomposition, a design project is transformed into several subprojects that are closely related to the teaching content of relevant courses and have clear node goals and test indicators. Some of these subprojects are the main body of the teaching content of courses, some are the subjects of students' training after class, or both after class. In the process of integrating all subprojects into corresponding teaching links and synchronizing the implementation with the teaching process, students have experienced a complete design process training, and their problem-solving ability has been greatly improved

In fact, The SPCGR teaching model has incorporated project-based teaching widely adopted by top universities in Europe and the United States. The advantage of project-based teaching lies in that it can effectively improve students' knowledge reorganization and application ability, while the process learning method can also improve students' systematic practice ability. However, this teaching method will destroy the integrity and sequence of the theoretical knowledge system, resulting in the fragmentation of students' knowledge retention. Most of the undergraduate courses have established a relatively mature knowledge system, and the course teaching is implemented according to the knowledge system. Therefore, although SPCGR teaching mode is integrated with project teaching, the project is carried out as an effective case for students to master knowledge, rather than the subject of knowledge. Therefore, it overcomes the shortcomings of project teaching and has obvious promotion significance for students to master systematic knowledge and further study

\section{SPCGR TEACHING MODE IS AN IMPORTANT SUPPORT FOR ENGINEERING CERTIFICATION}

In international engineering accreditation, emphasis is placed on student-centered education and results-oriented evaluation. In SPCGR teaching mode, both software tools and project settings are student-centered teaching links. By setting reasonable evaluation methods, students can be effectively assessed to the extent to which they can apply what they have learned.

The 2015 edition of Engineering Education Certification Standards emphasizes that the teaching process of undergraduate engineering education should revolve around complex engineering problems. According to the interpretation of the Washington Agreement, complex engineering problems should be understood as: Engineering problems in the training process of engineering education involve deep engineering knowledge and can solve one or more aspects of complex engineering problems, analyze modeling creatively to meet the diverse needs of engineering and other stakeholders. SPCGR teaching mode covers a variety of different types of teaching activities and teaching links, which is easy to realize the diversified assessment of a specific course, fundamentally changing the traditional teaching mode of 'one test determines a lifetime' evaluation method based on final examination. More importantly, through the effective decomposition and setting of complex problems from engineering practice, the training method that students complete projects with the help of software simulation tools can fully cultivate students' 
project implementation ability, which is difficult to achieve in the final examination paper. At the same time, the implementation of the teaching links set by the general courses in a certain major can ensure that all students can get the training of the ability to solve complex engineering problems, so as to realize the requirements of engineering certification that all students meet the standard, which reflects the biggest difference from the excellent engineer plan, discipline and science and technology competition.

\section{RELATIONSHIP BETWEEN SPCGR AND CDIO}

CDIO was first proposed by MIT in the 1990s. In the past 20 years, CDIO has emerged in Europe and America and attracted global attention. By selecting complex and high value-added engineering products, processes and system projects to be implemented in the learning process of students, the project is completed through the steps of conceivingdesigning-implementation-operation, et, the goal to train students to become modern engineers with full life cycle design and implementation capabilities of products or systems in a modern team environment can be easily achieved. In 2005, it was introduced into some universities in China, which has achieved good results [3 6]. CDIO success should have the conditions: (1) advanced and mature teaching philosophy. (2) Strong teachers and team support. (3) Sufficient teaching resources and funds.(4)Small class teaching.

The core idea of CDIO engineering education mode is integration, and construction course system from vertical level according to product realization process. SPCGR constructs course system from horizontal level through effective methods and means. Their similarity lies in: (1) both can be macro to the whole professional throughout the engineering education concept, but also can be micro to the specific implementation in a course. The subtle difference between CDIO and SPCGR is that CDIO is macro and SPCGR is micro. (2) Both CDIO and SPCGR focus on process management and internal quality assurance systems. The diversification of teaching links and teaching methods inevitably requires the importance of teaching process management and the construction of internal quality assurance system. Otherwise, formal teaching activities will make good ideas go to waste. At the same time, both teaching modes require teachers and students to invest more time, energy and even resources. Therefore, innovation of resource management and evaluation mechanism is very necessary.(3) Both CDIO and SPCGR attach great importance to the cultivation of students' export ability, that is, to improve students' ability to solve practical engineering projects by using learned knowledge, software tools and hands-on practice. The effective improvement of this ability is bound to be recognized and favored by employers.

\section{IMPLEMENTATION ADVANTAGES OF SPCGR}

As mentioned above, SPCGR can be implemented for a single course. In fact, the SPCGR teaching model can be extended to encompass a multi-disciplinary curriculum across the major. In engineering major or discipline, the knowledge structure among courses is closely connected, and the main courses have the characteristics of relevance, advancement and extensibility. For example, from the point of view of mechanical engineering, the close transverse and longitudinal cohesion relationship among engineering drawing, theoretical mechanics, material mechanics, mechanical principles, mechanical design, mechanical manufacturing technology base exist. The main courses have the corresponding mature aided design software. Thus, by forming design class curriculum group. selecting the same professional training of professional equipment engineering case, decomposing the task or index to many corresponding course in stages in teaching, and requiring students to use the corresponding software tools to complete, these methods can effectively guide students to have a strong interest in their major, improve their overall grasp of knowledge and application ability, and cultivate their ability to solve professional equipment design.

As an example, the major of machinery in our university focuses on training design talents of engineering machinery products according to the characteristics of the industry. Therefore, by choosing the lifting mechanism, working device and luffing mechanism of tower crane, wheel loader, truck crane, concrete pump truck as the design cases, permeating the design cases as design classes, mechanics courses solve kinematics characteristic and the mechanical principle courses complete scheme design and dynamics calculation, mechanical design courses solve the design of the component parts and structure, mechanical manufacturing technology courses complete parts of process design problem, and solution are all dependent on the corresponding software tools visualization realized, so that we can ensure that students achieve the targeted to solve the problem, It avoids the virtual problem solving training in the traditional teaching process, and enables students to feel the organic connection between the courses and the specific application methods, so as to achieve the goal of cultivating engineering application ability.

\section{EXAMPLE}

Mechanical design course is one of the main basic technical courses for mechanical majors, and also one of the ideal courses for students to train their engineering thinking and engineering training. After years of exploration and practice, the mechanical design teaching team of Shenyang Jianzhu University has adopted SPCGR teaching mode in recent years. The specific measures are as follows:

(1) The new curriculum syllabus has been formulated to clarify the SPCGR teaching mode and the proportion of its curriculum assessment results. The main course adopts the teaching method of combining in-class teaching and extracurricular learning, adopts SPCGR teaching mode, and emphasizes the training of students' ability to solve practical engineering problems with modern software tools. The teaching process is divided into classroom teaching, experimental teaching, and project practice. Proportion of assessment score: experimental score (20 points), project practice (20 points), and final score (60 points).

(2) The latest technological developments are integrated into part of the course. In the course of teaching, the knowledge of mechanism history, linear mechanism, parallel mechanism, flexible mechanism and the latest research progress as well as the latest design theories and methods have been appropriately 
supplemented. The cutting-edge knowledge is the material basis for implementing high quality SPCGR teaching.

(3) Software tool technology is introduced in the teaching process. In the course of classroom teaching, ADAMS (or MATLAB) software will run through the teaching content of mechanical principle course to complete the kinematics analysis of mechanical system. MATLAB, AUTOCAD and SOLIDWORKS software run through the course content of mechanical design, completing the design of main parameters of parts and drawing graphics. ANSYS is used to complete the structural analysis of mechanical parts and compare with the conventional design results. It should be emphasized that the use of software technology is mastered by students in their spare time through self-reinforcement and combined with project practice topics, which will benefit the subsequent courses and even the graduation project.

(4) The multi-level experimental teaching system is constructed. In order to adapt to the new curriculum requirements, to cultivate students' autonomous learning ability, the multi-level experimental teaching system combining the cognitive, verification, comprehensive and independent innovation design \& production experiments has been constructed. The goal of combining analytical, exploratory experiment and innovative design is realized. The laboratory is open 12 hours a day to provide students with open space and sufficient experimental resources.

(5) The project resource database which is matched with the teaching content is developed. In order to better cooperate with SPCGR teaching and achieve the expected teaching effect, a project resource library matching the teaching content is developed. The developed project and the regular homework and the final examination just form the knowledge and ability complement each other.

(6) During the study period, several large assignments were arranged according to the implementation process of the project, and all the assignments were taken as the assessment basis of the course. The whole teaching process was also closely centered on the theoretical knowledge involved in the large assignments. For example, the major assignment topics listed in the course of Mechanical Principles and Mechanical Design are as follows: a) Submit research report on wheel loader. b) Complete the degree of freedom analysis and synthesis of the working device. c) Complete kinematics modeling and MATLAB simulation. d) The 2D diagram of each part of the main mechanism of the working device is given, and the 3D modeling and assembly is completed by using SOLIDWORKS.e) ANSYS structural analysis of rocker arm. Mechanical principle course completes the first three parts (That is, stages a), b) and c)), and the rest to mechanical design. This teaching mode brings students almost real design process training.

\section{CONCLUSION}

In the context of engineering education reform and engineering certification, based on China's national conditions and school conditions, and by referring to CDIO and other advanced teaching ideas, the SPCGR teaching mode that is universal to engineering education is proposed. The SPCGR teaching model in a single course emphasizes the organic integration between project training, software use, theoretical teaching and experimental teaching. The curriculum focuses more on the relevance of knowledge system, the level of project setting and the seamless connection of different software tools, so as to achieve SPCGR in the true sense. In recent 5 years, two levels of SPCGR teaching mode has been tried in a few courses of mechanical engineering major in our school, and good teaching effect has been achieved.

It should be noted that SPCGR teaching model puts forward higher requirements for teachers and teaching teams. In addition to the professional quality and professional ability of teachers, they are mainly reflected in: (1) The project can reflect the integrity, frontier and extensibility, which requires a large proportion of teaching and scientific research teachers, especially professors, to participate in the setting, organization and implementation of the project. (2) The teaching echelon is formed reasonably, especially the participation of young teaching assistants to complete the learning guidance of software tools, the guidance and evaluation of large project assignments and the implementation of research-based experimental teaching. (3) The teaching team should be composed of teachers with strong sense of responsibility and dedication, and the project leader should have strong organizational ability. SPCGR teaching will obviously bring teachers many times of workload. It is impossible to do well without a strong sense of responsibility and dedication in order to ensure orderly teaching process, fair and just teaching evaluation and expected teaching effect.

\section{REFERENCES}

[1] Gu Peihua et al. Reunderstanding engineering education, Beijing: Higher Education Press, 2009. (In Chinese).

[2] A.Hoyndorf, H. Haider.The "Not Letting Go" phenomenon:accuracy instructions can impair behavioral and meta cognitive effects of implicit learning processes[J]. Psychological research, 2009, vol 73, pp:695-706.

[3] Shuzi Yang. Talk about my understanding of CDIO-Engineering Culture Education, [J]. China University Education, 2008, vol 9 ,pp 6-7. (In Chinese).

[4] Hao Ruiqin et al. Research on innovation Talent Training Mode Reform for Mechanical Majors in architecture Colleges [J]. Mechanical Design, 2016, vol 8, pp:103-106. (In Chinese)

[5] Han Zeguang et al. Innovative scheme of Mechanical backbone Basic Course based on CDIO education concept [C], Research on Mechanical Design Teaching, Beijing: Machinery Industry Press, 2012, pp96-99. (In Chinese).

[6] Li Xinghua.The discuss on the Machine Design course teaching method.Springer Lecture Notes in Electrical Engineering, 2011, 132,pp671-675 